\title{
Fuel, Preheat Effects on Soot-Field Structure in Laminar Gas Jet Diffusion Flames Burning in 0-g and 1-g
}

\author{
BOGDAN KONSUR AND CONSTANTINE M. MEGARIDIS,* \\ Department of Mechanical Engineering, University of Illinois at Chicago, Chicago, IL 60607, USA \\ DEVON W. GRIFFIN \\ Microgravity Combustion Science Branch, NASA Lewis Research Center, Cleveland, OH 44135, USA
}

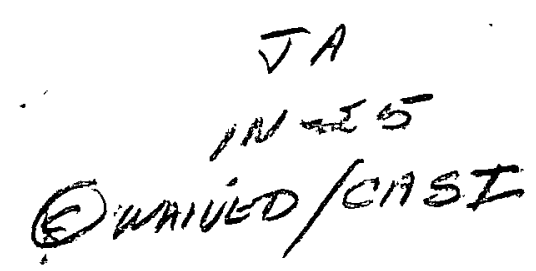

\begin{abstract}
An experimental investigation conducted at the 2.2-s drop tower of the NASA Lewis Research Center is presented to quantify the influence of moderate fuel preheat on soot-field structure within $0-\mathrm{g}$ laminar gas jet diffusion flames. Parallel work in 1-g is also presented to delineate the effect of elevated fuel temperatures on soot-field structure in buoyant flames. The experimental methodology implements jet diffusion flames of nitrogen-diluted acetylene fuel burning in quiescent air at atmospheric pressure. Fuel preheat of $\sim 100 \mathrm{~K}$ in the $0-\mathrm{g}$ laminar jet diffusion flames is found to reduce soot loadings in the annular region, but causes an increase in soot volume fractions at the centerline. In addition, fuel preheat reduces the radial extent of the soot field in $0 \mathrm{gg}$. In $1 \mathrm{-g}$, the same fuel preheat levels have a more moderated influence on soot loadings in the annular region, but are also seen to enhance soot concentrations near the axis fow in the flame. The increased soot loadings near the flame centerline, as caused by fuel preheat, are consistent with the hypothesis that preheat levels of $\sim 100 \mathrm{~K}$ enhance fuel pyrolysis rates. The results show that the growth stage of particles transported along the soot annulus is shortened both in $1-\mathrm{g}$. and $0-\mathrm{g}$ when elevated fuel temperatures are used. ( 1998 by The Combustion Institute
\end{abstract}

\section{INTRODUCTION}

Soot is a major source of the radiant heat transfer from a flame to the surroundings [1]. The increased heat transport rates and loss of efficiency associated with soot degrade the performance of many combustion devices. In addition, the release of fine soot particulates in exhaust gases leads to environmental pollution which has become an increasing concern [2]. On the other hand, the formation and presence of soot in adequate quantities is desirable within combustion furnaces because soot radiation improves the thermal efficiency of these devices prior to a programmed burnout. Thus, effective control of soot formation processes in combustion is highly desirable.

Turbulent flames are of utmost practical interest, but they feature high temporal and spatial fluctuations which limit the effective use of diagnostic instrumentation employed successfully in laminar flames. Consequently, most of the current knowledge regarding soot processes has been derived from buoyant laminar flame experiments [3]. However, the effect of buoyancy in turbulent flames is known to be locally

\footnotetext{
*Corresponding author. E-mail: cmm@uic.edu
}

negligible. To this end, nonbuoyant flames burning in low gravity offer themselves as an attractive and promising platform to gain a better understanding of soot mechanisms in practical systems [4]. The effects of buoyancy can be eliminated temporarily in drop towers which sustain brief intervals of reduced gravity-typically lower than $10^{-3} \mathrm{~g}$ - extending up to several seconds at a time. Such an environment is referred to as microgravity or $0-\mathrm{g}$. Microgravity facilities have been employed [5, 6] to show that nonbuoyant flames are longer, wider and sootier than their normal-gravity counterparts.

Sunderland et al. [7] recently verified the existence of smoke point in laminar nonbuoyant flames. As reported in [6] and [7], microgravity flames operating above their smoke point displayed a blunt tip and much broader sootcontaining regimes in comparison to their buoyant counterparts. Mortazavi et al. [8] established that residence times in microgravity laminar jet diffusion flames with $\mathrm{Re}=\mathrm{O}(100)$ tend to be proportional to burner diameter and inversely proportional to burner exit velocity. This offers the capability to alter residence times in nonbuoyant laminar jet diffusion flames when varying the burner exit diameters

COMBUSTION AND FLAME 116:334-347 (1999) (C) 1998 by The Combustion Institute Published by Elsevier Science Inc. 
and velocities [4]. Conversely, flame residence times for buoyant laminar diffusion flames are rather limited since they are controlled by buoyancy and are relatively insensitive to burner diameter or burner exit velocity distributions.

The first quantitative definition of the sootfield structure within laminar microgravity jet diffusion flames was presented by Megaridis et al. [9] for flames operated well above their smoke point. The experimental methodology involved a full-field laser-light extinction technique $[10]$ and jet diffusion flames of nitrogendiluted (50\% vol) acetylene fuel burning in quiescent air at atmospheric pressure. The work was conducted at the 2.2-s drop tower of the NASA Lewis Research Center (NASA-LeRC). Parallel work on 1-g flames was also presented in [9] to facilitate comparisons on the effect of gravity on the soot fields. As reported in [9], the soot spatial distributions in $0-\mathrm{g}$ flames did not change in a detectable manner after $1 \mathrm{~s}$ within a typical 2.2-s experiment. During that period, the soot field was shown to sustain a pronounced annular structure throughout the luminous nonbuoyant-flame zone. The maximum soot volume fraction measured at $0-\mathrm{g}$ was nearly a factor of two higher than that at 1-g, thus confirming the enhanced sooting tendency of nonbuoyant flames [4].

Greenberg and $\mathrm{Ku}$ [11] presented a similar study and reported trends that matched those of Megaridis et al. [9] for the 50\% (vol) nitrogendiluted acetylene fuel. Furthermore, they examined pure acetylene flames and reported similar trends with respect to the influence of gravity on maximum soot volume fractions and flame cross-section-averaged soot loadings. Both studies $[9,11]$ clearly demonstrated the improved spatial resolution afforded in microgravity flames compared to their normal-gravity counterparts.

Reactant temperature at the burner exit is an important operating parameter in laminar gas jet diffusion flames. Fuel and/or oxidizer preheat can be used at 1-g as a means of altering flame temperature, and in turn, soot formation [3]. This effect was addressed first by adding inert diluents to the fuel or the oxidizer stream; see [12] and references cited therein. In most cases, however, the overlapping effects of lower fuel concentrations and lower flame tempera- tures resulting from inert dilution could not be evaluated separately. Only recently, Gülder and Snelling [13] and Gülder [14] circumvented the simultaneous effects of dilution and temperature by opting for an experimental arrangement in which the reactant streams were heated to elevate flame temperatures. These researchers preheated both fuel and oxidizer in a manner that increased the adiabatic flame temperatures by at least $70 \mathrm{~K}$. It was reported in $[13,14]$ that reactant preheat levels of the order of $180 \mathrm{~K}$ increased peak soot loadings in propane, ethylene, and propylene axisymmetric flames by up to $30 \%$. It is noted, however, that the conclusions reached in Refs. [13, 14] were based on line-of-sight extinction measurements, which tend to oversimplify soot dynamics in axisymmetric flames featuring steep gradients along the radial coordinate. Thus, more detailed sootfield measurements are needed in 1-g. Furthermore, no equivalent studies exist on the corresponding effects in nonbuoyant flames.

Fuel preheat is frequently required in fuel additive studies in order to incorporate seeding agents into the fuel stream [15]. To this end, the effects of fuel preheat on soot formation need to be resolved and quantified first before additive seeding effects are examined. As fuel additive use is targeted for practical turbulent flames, the use of nonbuoyant flames for resolving fuel preheat effects appears justified. The current study extends our previous experimental work performed in microgravity [9] and evaluates the influence of moderate fuel preheat on soot-field structure within 0-g laminar gas jet diffusion flames. Parallel work in $1-\mathrm{g}$ is also presented to delineate the effect of elevated fuel temperatures on soot-field structure in buoyant flames. While fuel temperature variations have little influence on residence times in $1-g$ [4], they have a much more significant effect in 0 -g. Thus, as residence times play an important role in soot formation, the trends for fuel preheat in 1-g may be different than those in $0-\mathrm{g}$. The primary objective of this paper is to quantify this effect by comparing soot volume fractions under preheated and unpreheatedfuel conditions both in the presence and absence of gravity. Furthermore, the current work aims at expanding the soot database available for nonbuoyant flames which can be used to 
TABLE 1

Flame Conditions

\begin{tabular}{lccccr}
\hline Case & $\begin{array}{c}\text { Fuel Exit Temp. } \\
\left({ }^{\circ} \mathrm{C}\right)\end{array}$ & $\begin{array}{c}\text { Fuel Flowrate } \\
(\mathrm{mg} / \mathrm{s})\end{array}$ & $\begin{array}{c}\text { Fuel Flowrate } \\
\left(\mathrm{cm}^{3} / \mathrm{s}\right)\end{array}$ & $\begin{array}{c}\text { Exit Velocity } \\
(\mathrm{cm} / \mathrm{s})\end{array}$ & $\begin{array}{c}\text { Exit Reynolds } \\
\text { Number }\end{array}$ \\
\hline I & 23 & 1.6 & 1.5 & 74.6 & 96 \\
II* & 23 & 2.2 & 2 & 99.5 & 128 \\
III & 120 & 2.2 & 2.7 & 132.1 & 105 \\
IV & 160 & 2.2 & 2.9 & 145.5 & 98 \\
\hline
\end{tabular}

* Base case.

perform additional tests of recently developed soot submodels (see [16], for example) which have the potential, when used in conjunction with fluid transport models [17], to become powerful predicting tools in combustion design.

\section{EXPERIMENTAL SETUP AND CONDITIONS}

The laminar gas jet diffusion flames studied herein were operated at atmospheric pressure and were based on a $1.6-\mathrm{mm}$ inner diameter stainless-steel burner which was positioned vertically in the experimental apparatus. The burner tip had an outside taper of $30^{\circ}$ and was positioned $\sim 50 \mathrm{~mm}$ above a base plate which held the nozzle and the spark ignitor assembly. The nozzle length-to-diameter ratio was around 55 to ensure that fully developed flow emerged from the burner tip. The fuel mixture consisted of $50 \%$ (volume) $\mathrm{C}_{2} \mathrm{H}_{2}-50 \% \mathrm{~N}_{2}$ and was issued into quiescent air contained in a rectangular chamber with dimensions $30 \mathrm{~cm} \times 21 \mathrm{~cm} \times 43$ $\mathrm{cm}$. The base fuel flow rate of $2.2 \mathrm{mg} / \mathrm{s}$ was selected because it defined flame sizes that provided adequate resolution of the soot fields both in 1-g and 0-g [9]; the flame luminosity lengths were between 25 and $30 \mathrm{~mm}$. The mass flow rate of $2.2 \mathrm{mg} / \mathrm{s}$ corresponds to a volume flow rate of $2 \mathrm{~cm}^{3} / \mathrm{s}$ at room temperature and atmospheric pressure. A second set of experiments was conducted at a lower fuel flow rate of $1.6 \mathrm{mg} / \mathrm{s}$. Two preheated-fuel temperatures were studied for the base mass flow rate of 2.2 $\mathrm{mg} / \mathrm{s}: 120^{\circ} \mathrm{C}$ and $160^{\circ} \mathrm{C}$. These preheat levels correspond to an increase in adiabatic flame temperature (with molecular dissociation) by 7 $\mathrm{K}$ and $10 \mathrm{~K}$, respectively, compared to the unpreheated-fuel case. As will be noted later, however, the effect of the employed fuel preheat levels on fuel pyrolysis rates-and thus on soot inception rates-may not be negligible. Table 1 lists four burner exit conditions for the flames studied in this work. Two conditions (I and II) involved unpreheated fuel, while the other two (III and IV) featured preheated-fuel temperatures of 120 and $160^{\circ} \mathrm{C}$, respectively. All burner exit flow conditions listed in Table 1 produced nonflickering flames in normal gravity as well as within the short time period available for measurements in the drop tower. All 1-g flames corresponding to the conditions listed in Table 1 emitted no soot from their closed conical tip, whereas their nonbuoyant counterparts released soot from their open tip. The smoke point of the diluted unpreheated acetylene fuel at $0-\mathrm{g}$ was determined to be in the range from 0.77 to $1.1 \mathrm{mg} / \mathrm{s}\left(0.7\right.$ to $1 \mathrm{~cm}^{3} / \mathrm{s}$ at room temperature and atmospheric pressure).

The experimental rig is the same one used in our previous study [9] which was conducted in the 2.2-s drop tower of NASA-LeRC. Detailed information on the drop tower facility can be found in [18]. Each microgravity experiment lasts for $2.2 \mathrm{~s}$, during which data are collected continuously. Diagnostic instrumentation includes laser-light extinction for determination of soot volume fraction distributions and direct imaging of the flame. The flame luminosity throughout each drop test is recorded on a Super Video Home System (SVHS) tape, which can be subsequently analyzed to determine luminous flame dimensions. Video signals are channeled to separate offboard recorders via fiberoptic cables. Experiments are fully automated and are controlled via an onboard computer. All functions are powered by a $28-\mathrm{V}$ battery pack. A typical drop sequence starts 
with the rig release from the top of the tower (onset of microgravity), and proceeds with fuel flow initiation, ignition (via spark), flame development, and finally, impact on an airbag at the bottom of the tower (end of 2.2-s-long microgravity period).

Fuel preheat is achieved by thermocouple sensors, temperature controllers, and heating tapes wrapped around the fuel feed lines. After passing through an electronic rotameter first, the fuel is directed through a $50-\mathrm{cm}^{3}$ cylinder packed with stainless steel beads maintained at the desired preheat temperature by $\mathrm{AC}$ heaters drawing external (off-rig) power. The power cable of these heaters is disconnected shortly before the release of the drop package and the concomitant onset of $0 \mathrm{~g}$. The thermal mass of the beads was sufficient to maintain the fuel temperature at the desired level for a period of $1-2$ min between cutting off power to the AC heaters and the release of the experimental package from the top of the tower. A DC heater (powered by the battery pack of the rig) encased the burner tube and was used to maintain the desired temperature there. The above design allowed operation in either unpreheated or preheated mode by activating appropriate elements of the experimental setup.

Soot volume fraction distributions within the flames were determined via a full-field laserlight extinction technique [10] which is based on principles of optical tomographic reconstruction and is capable of determining transient soot spatial distributions in laminar axisymmetric flames. The instrumentation for these measurements has been described in detail in Ref. [9]. In this technique, a laser light beam $(\lambda=674.9$ $\mathrm{nm}$ ) is spatially filtered, expanded and collimated to a cylinder approximately $50 \mathrm{~mm}$ in diameter before passing through the soot-laden flame. Soot scatters and absorbs light depending on the size of the primary and aggregated particles [19], producing a shadow-like image at the back of the flame. The laser beam is chopped at a frequency of $8 \mathrm{~Hz}$ to allow correction for residual flame luminosity that reaches a CCD camera detector. The images viewed by the CCD camera through a laser-line filter are recorded at a rate of 30 frames per second and are used for data reduction after the completion of each $0-\mathrm{g}$ experiment. When the image frame of the soot field is compared to a reference frame taken before the flame was ignited, the line-of-sight fractional absorption can be calculated after an appropriate correction for flame luminosity is performed. Typical absorption levels are of the order of $25 \%$, being occasionally as high as $35 \%$, thus satisfying the optically-thin medium assumption. Each soot-field image (as seen by the camera) is filtered using a $3 \times 3$ low-pass filter, and the individual vertical position $(Z)$ data is 5-pixel bin averaged along the radial coordinate to smooth out the effect of spatial field irregularities caused by lens contamination. The physical dimensions of each pixel along the radial and axial coordinates of the original unbinned image plane are 87 and 72 $\mu \mathrm{m}$, respectively. From each horizontal intensity profile ( $Z=$ constant), the radial distribution of soot volume fraction is determined using a three-point Abel deconvolution algorithm [20], and Rayleigh scattering theory [21] with a specific value of the refractive index of soot $(1.57-0.56 i)$. As shown by Köylü and Faeth [22], discrepancies between the Rayleigh approximation and the more detailed RayleighDebye-Gans (RDG) scattering theory [23] are largest at short wavelengths $(\sim 500 \mathrm{~nm})$ for heavily sooting fuels. The moderate laser wavelength of the current work $(674.9 \mathrm{~nm})$ suggests that these discrepancies are not significant. A curve-fitting procedure is used to define the center of the sooting region at each height, and the soot volume fraction on either side of the axis is 3-point averaged to obtain the final values for each image. The adequacy of the automated centering procedure was validated using a sensitivity analysis performed by picking the center manually and reinverting the data. The two sides of each profile were eventually symmetrized by averaging the two respective values of soot volume fraction at each radial location.

\section{RESULTS AND DISCUSSION}

\section{Luminous Flame Appearance in 0-g}

Although visible flame appearance does not define the location of the reaction zone, it provides an approximation of the spatial extent of the soot field. Detailed observations of lumi- 

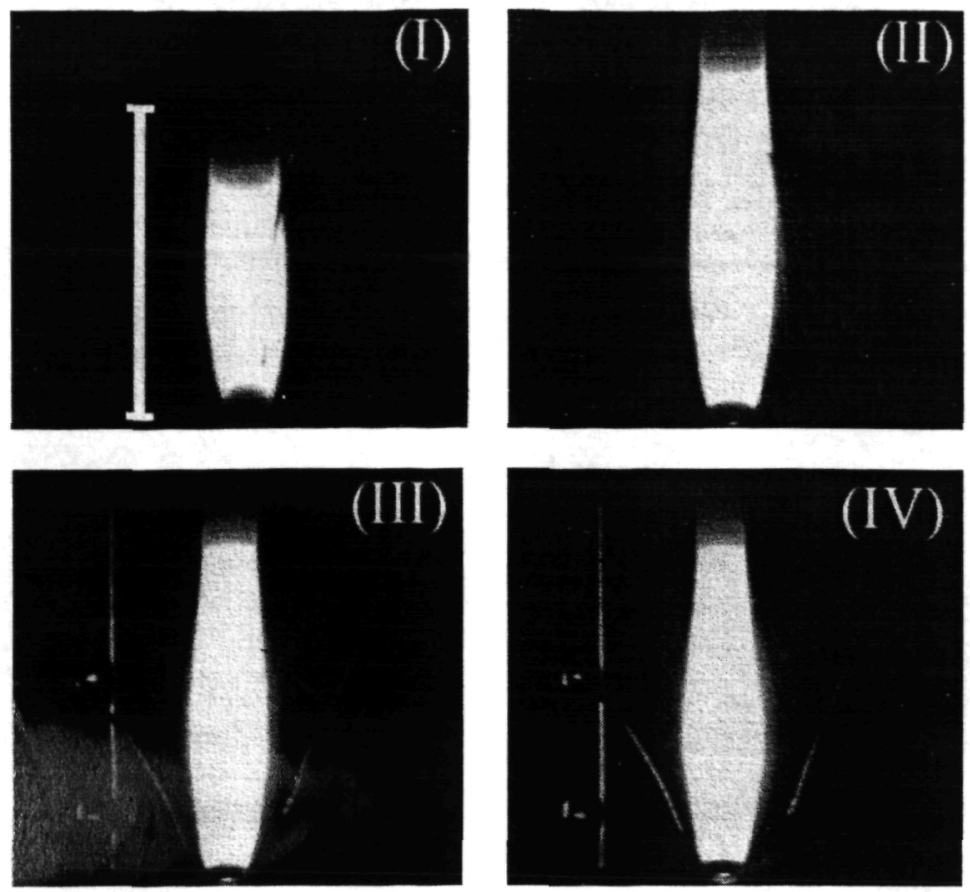

Fig. 1. Luminous flame images in 0 -g: I) low flow rate with unpreheated fuel, II) base flow rate with unpreheated fuel, III) fuel preheated to $120^{\circ} \mathrm{C}$, and IV) fuel preheated to $160^{\circ} \mathrm{C}$. These images were captured after the brief initial transients in 0-g. The illuminated burner tip can be seen at the base of each flame image. The spark ignition wires are also visible on either side of the preheated flames (III and IV). These wires were positioned far enough from the flame to minimize interference with the combustion process. The vertical scale drawn in (I) corresponds to a length of $25 \mathrm{~mm}$. nous zone development after ignition in $0-\mathrm{g}$ showed the initial transients to be complete before the half-way temporal point of a drop experiment $(\sim 1 \mathrm{~s})$. A typical flame appeared to remain unchanged thereafter and until the latter part of a drop, when some pulsing was consistently seen. The pulsing was attributed to the established contact between the experiment rig and the drag shield at around 1.7-1.8 s into a 0 -g experiment. Figure 1 displays the luminous images of Flames I-IV, as captured from the side after the brief initial transients in 0 -g. The soot-emitting character of all 0-g flames examined in this work made the determination of a visible height impossible; notice the gradual darkening of flame tip with height in Fig. 1. The lengthwise extent of Flame I (low flow rate) is noticeably shorter compared to that of the base flame (II), although the maximum luminous width is nearly identical for both flames. The differences in shapes II-IV in Fig. 1 also reveal that fuel preheat has a visible effect on the structure of the soot field. More specifically, the base and the tip of Flames III and IV (preheated fuel) are considerably narrower than those of Flame II (base flame; unpreheated fuel). It is expected that these differences in the spatial extent of the soot field are also accompanied by differences in the local values of soot volume fraction in the in-flame region.

\section{0-g Soot Fields}

Soot fields in 0-g laminar jet diffusion flames anchored on a burner of diameter of $1.6 \mathrm{~mm}$ (Reynolds number of the order of 100) were analyzed in [9] as a function of time to evaluate their transient postignition character. Figure 2 displays two unprocessed instantaneous shadow-like images of the soot field as viewed by the CCD camera of the extinction setup during a drop experiment at $0.5 \mathrm{~s}$ and $1.2 \mathrm{~s}$ after the release of the package. Fuel ignition occurred $0.3 \mathrm{~s}$ after the onset of microgravity. The flame conditions corresponding to these images are those of Case II in Table 1. The apparent differences of the soot shadow at the upper half of the images of Fig. 2 confirm the changing character of the soot field after ignition in $0-\mathrm{g}$ $(0.3 \mathrm{~s})$. As reported in [9], the establishment of the soot field in these flames is completed within $1 \mathrm{~s}$ after the onset of microgravity. This was also verified in the current study for all flame conditions listed in Table 1.

A series of images similar to those depicted in Fig. 2 were utilized to produce radial distribu- 

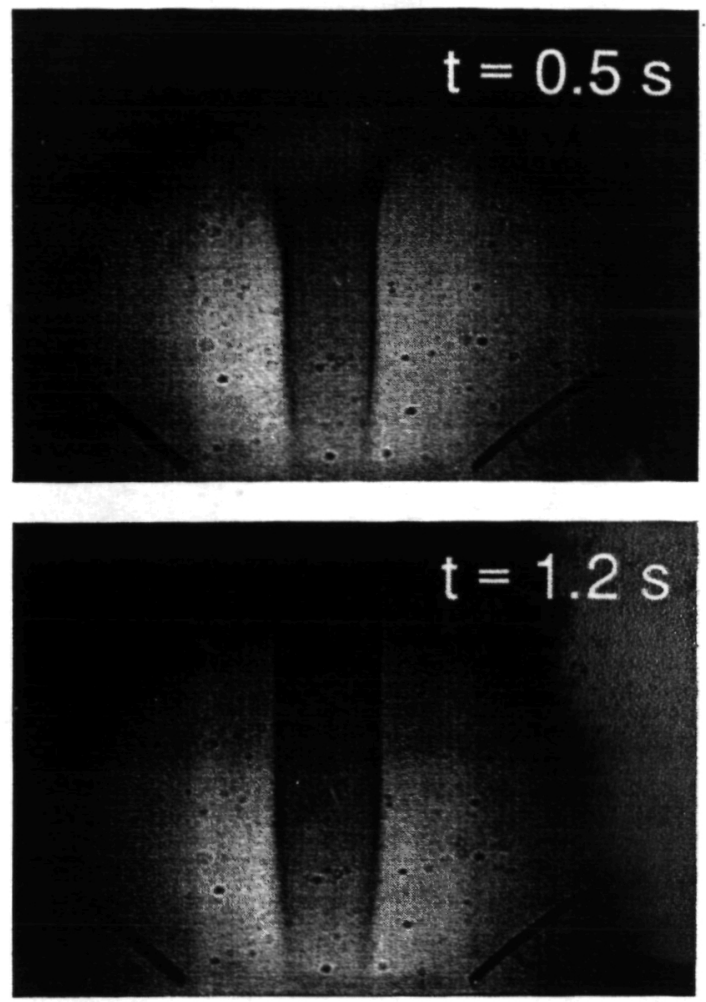

Fig. 2. Instantaneous shadow-like images of the soot field as viewed (unprocessed) by the CCD camera of the extinction setup during a drop experiment at $0.5 \mathrm{~s}$ and $1.2 \mathrm{~s}$ after the onset of microgravity. Illumination is provided by the expanded laser beam. The burner mouth is located directly below the middle of the bottom edge of each image. The two spark ignitor wires can be seen on either side of the soot cloud. The specks scattered within these fields are spatial noise caused by unremovable lens contamination.

tions of soot volume fraction $\left(f_{v}\right)$ at distinct axial stations above the burner tip of each flame. The specific heights examined in 0 -g are $Z=$ $10,15,20,25$, and $30 \mathrm{~mm}$. The spatial soot distribution at each height $Z$ was obtained by averaging the respective distributions acquired in two to three drop experiments which were conducted using identical operating conditions. A data rejection procedure was implemented in this process which was based on utilizing radial soot distributions which were within a narrow range of one another $(\sim 15 \%)$. Figure 3 displays the radial variations of $f_{v}$ throughout the four microgravity flames (I to IV; see Table 1). This figure shows clearly-as also reported in [9]-that the soot distributions maintain a welldefined annular structure throughout the entire luminous flame zone, even near the tip (Fig. 3e). Similar confinement of the soot aerosol in an annulus near the flame tip was also reported by Honnery and Kent [24] for their long ethylene/air buoyant jet diffusion flames. While the annular structure of the soot field is ubiquitous at low heights of laminar jet diffusion flames, its persistence up to the luminous flame tip is characteristic only of fuel flow rates that are sufficiently higher than the smoke point. This can be explained by the fact that high fuel flow rates cause excessive soot loadings in the annular region, thus reducing the probability for complete burnout of the particles before they reach the flame tip.

The radial distributions in Fig. 3 also show that the lower exit momentum of the fuel jet in Flame I causes a widening of the soot field compared to the rest of the flames. This trend is maintained at all heights and emphasizes the importance of jet momentum in flame structure in 0-g. As the fuel exit velocity increases from Flame I to IV, the soot annulus moves closer to the flame axis. Regarding the effect of fuel preheat, two observations can be made from the soot distributions shown in Fig. 3. First, the radial location of the soot annulus is nearly the same for the two flames with preheated fuel (III and IV). Second, although the soot volume fraction remains always higher on the annulus compared to the center, the soot concentrations in the vicinity of the flame axis rise with fuel preheat (compare curves II and III or IV at $Z=$ $30 \mathrm{~mm}$, for example).

Figure 4 compares the streamwise variation of (a) maximum and (b) on-axis soot volume fraction at each height $Z$ for all 0 -g flames. As the radial distributions in Fig. 3 indicate, the maximum values of $f_{v}$ at a fixed height always correspond to the soot annulus in the 0 -g flames examined in this work. Figure 4a includes the values of $f_{v}$ on the soot annulus of a flame identical to Flame II as reported in Ref. [9], and shows good repeatability of the measurements. The soot-releasing character of all flames is confirmed by the nonzero value of $f_{v}$ near the flame tip $(Z \approx 30 \mathrm{~mm})$. Figure $4 \mathrm{a}$ shows that the overall maximum value of $f_{v}$ is $\sim 14 \mathrm{ppm}$ and is achieved near $Z=20 \mathrm{~mm}$ of Flame II (unpreheated fuel). In the two preheated-fuel flames, the soot volume fractions peak at a lower height $(Z=15 \mathrm{~mm})$ and decline there- 


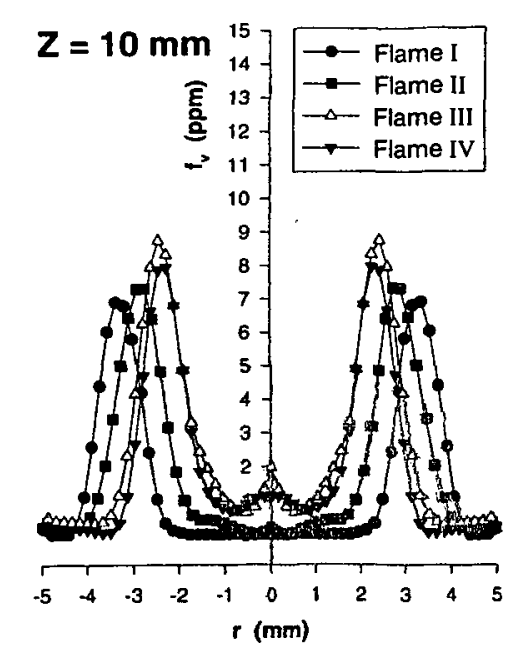

(a)

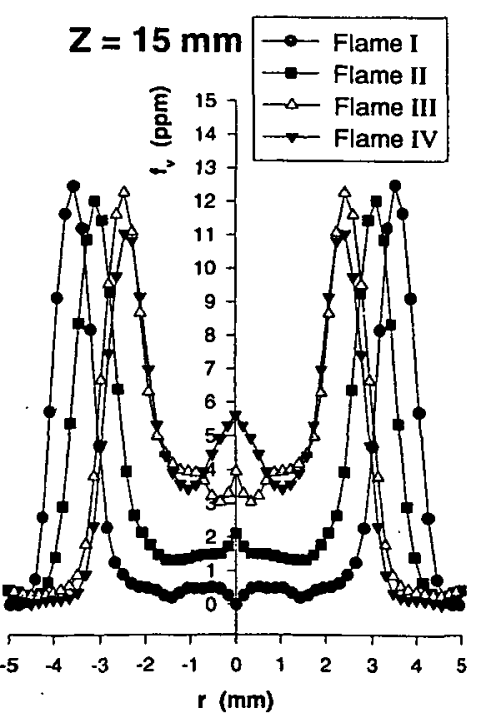

(b)

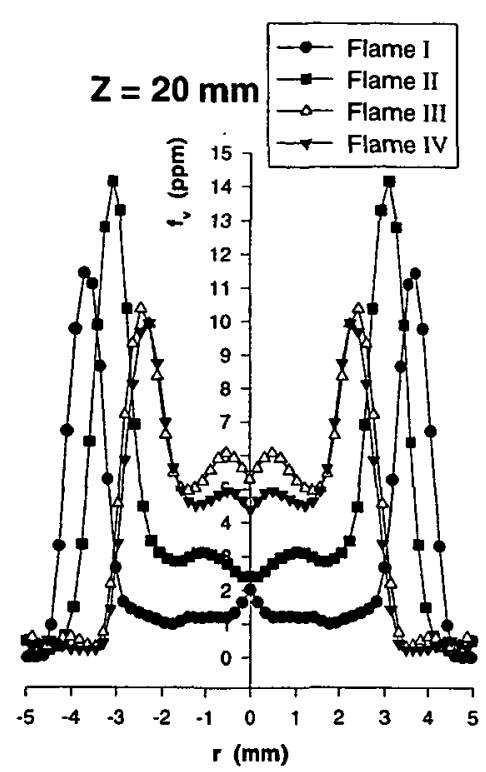

(c)

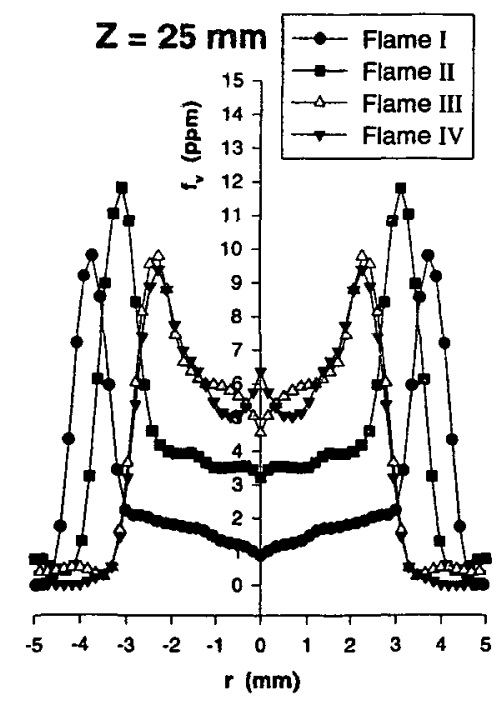

(d)

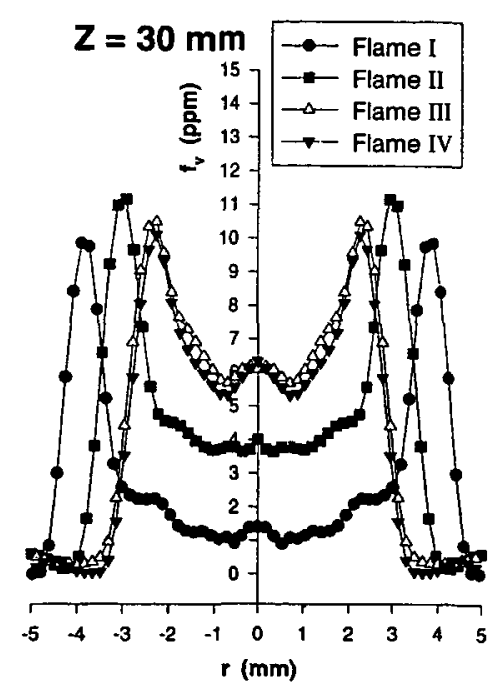

(e)

Fig. 3. Radial distributions of soot volume fraction $\left(f_{v}\right)$ at five distinct axial stations above the burner mouth $(Z=10 \mathrm{~mm}$, $15 \mathrm{~mm}, 20 \mathrm{~mm}, 25 \mathrm{~mm}$, and $30 \mathrm{~mm}$ ) of the four microgravity flames examined (I to IV; see Table 1). The radial distributions for Flame I were obtained at $1.4 \mathrm{~s}$ into microgravity, while the distributions for Flames II-IV were obtained at $1.2 \mathrm{~s}$ into $0 \mathrm{-g}$. These instants represent the apparent steady state of the flames following the initial soot-field transients [9].

after. This observation marks an important difference between unpreheated and preheatedfuel flames in 0 -g and reveals that moderate fuel preheat shifts the maximum soot volume fraction to lower heights, i.e., earlier residence times. Some important conclusions can be inferred from the curves seen in Fig. 4 when taking into account residence time considerations.
Estimates of flow residence times were produced for the base case flame (II) using the soot cloud as a flow tracer during a typical drop experiment, and taking advantage of the transient character of the extinction field after ignition in 0-g (see Fig. 2). The flow residence time through the luminous zone of Flame II was approximately $0.3 \mathrm{~s}$. A similar procedure for the 


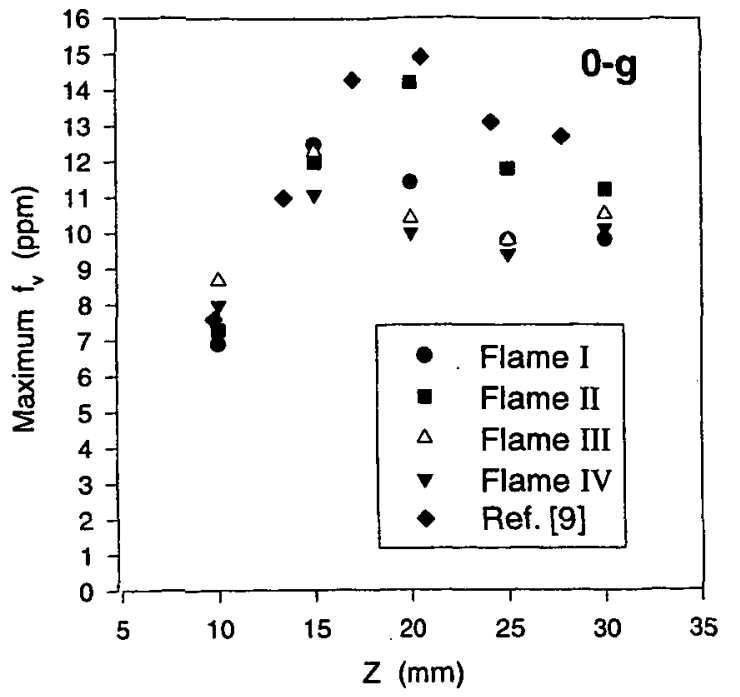

(a)

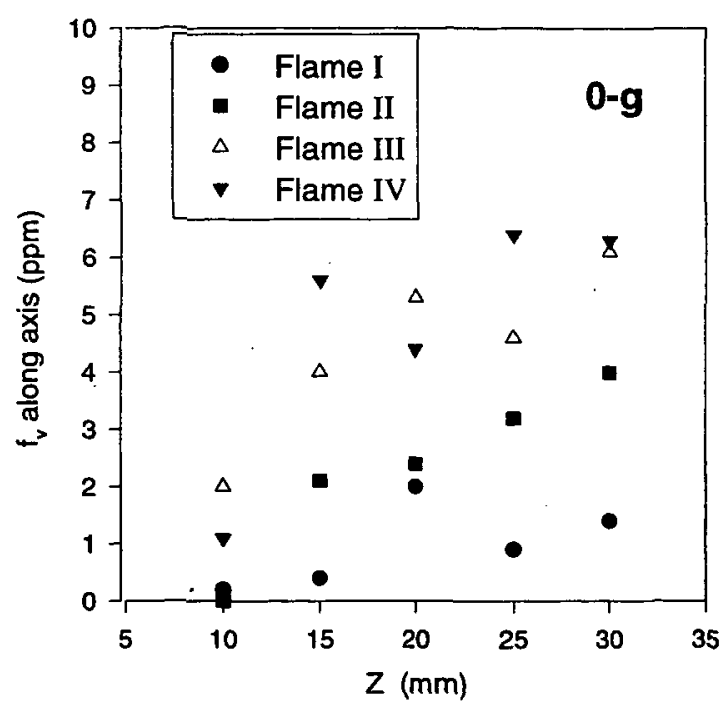

(b)

Fig. 4. Comparison of the streamwise variation of (a) maximum and (b) on-axis soot volume fraction at each height $Z$ for all $0-\mathrm{g}$ flames.

lower flow rate $(1.6 \mathrm{mg} / \mathrm{s})$ produced a residence time of about $0.4 \mathrm{~s}$ in Flame I. These residence times scale approximately with inverse flow rate, in agreement with the analysis of Mortazavi et al. [8]. The above simplified measurements also confirm that, in 0-g laminar jet diffusion flames with $\operatorname{Re}=O(100)$, residence times are inversely proportional to burner exit velocity for a fixed burner size [8]. The fuel exit velocities listed in Table 1 agree with the estimate that Flame I features a residence time that is $\sim 33 \%$ longer compared to Flame II. The gradually increasing fuel exit velocities from Flame II to IV (see Table 1) cause reductions in residence times by $25 \%$ and $\sim 32 \%$ in Flames III and IV, when compared to Flame II. For given fuel, extended flame residence times contribute to higher soot loadings, while lower fuel flow rates reduce soot concentrations. It is seen that the values of $f_{v}$ shown in Fig. 4a for the annular regions of Flames I and III or IV are very similar near the upper end of these flames (see values at $Z=\mathbf{3 0}$ $\mathrm{mm}$ ). It appears that the lower sooting tendency caused by the reduced fuel flow rate in Flame I is neutralized by the soot-promoting influence of the longer residence time in this flame compared to Flame III or IV. Thus, the two competing effects result in ultimate values of $f_{v}$ on the soot annulus which are nearly identical in Flames I, III, and IV. On the other hand, the combined effect of these two factors in Flame II results in soot volume fractions that are consistently higher than those in all other flames (see Fig. 4a). An exception to this trend is seen at the lowest measured height $(Z=10 \mathrm{~mm})$, where the preheated-fuel flames display slightly higher soot concentrations than the cool-fuel flames. This may be partially due to enhanced fuel pyrolysis rates caused by the elevated fuel temperatures. Enhanced fuel pyrolysis rates augment soot inception, possibly causing the higher soot loadings in the preheated flames at this height. This possibility is further supported by Fig. $4 \mathrm{~b}$ where the soot volume fraction evolution along the flame axes verifies that soot concentrations in the flame core are promoted by fuel preheat. The significant scatter of the data plotted in Fig. $4 \mathrm{~b}$ is attributed to the increased error in the tomographic inversion procedure towards the flame centerline [20], but the overall trends shown in this figure are believed to be accurate. The strong soot-enhancing influence of fuel preheat on the flame centerline cannot be attributed to a residence time effect, because Flames III and IV feature shorter residence times compared to Flame II. However, fuel preheat by $\mathrm{O}(100 \mathrm{~K})$ may enhance fuel pyrolysis rates, although such preheat levels correspond to an increase in adiabatic flame temperature of less than $10 \mathrm{~K}$. 

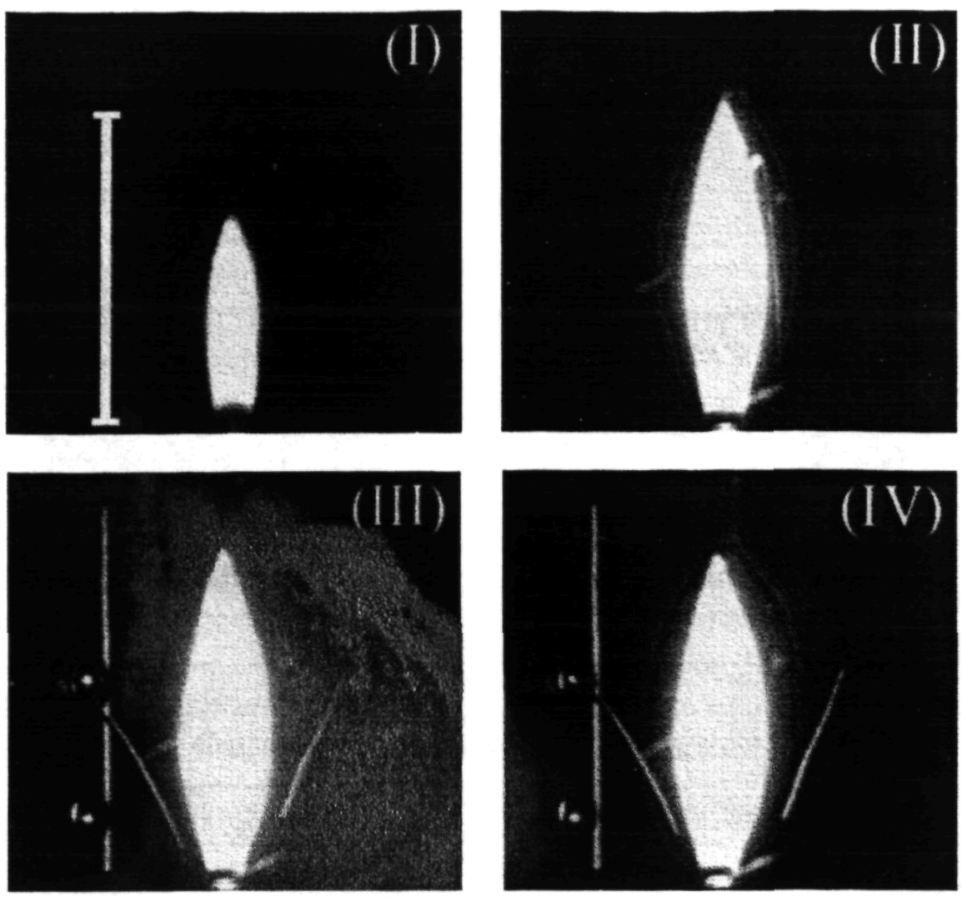

Fig. 5. Luminous flame images in 1-g: I) low flow rate with unpreheated fuel, II) base flow rate with unpreheated fuel, III) fuel preheated to $120^{\circ} \mathrm{C}$, and IV) fuel preheated to $160^{\circ} \mathrm{C}$. The illuminated burner tip can be seen at the base of each flame image. The spark ignition wires along with some other background instrumentation are also visible on either side of the preheated flames (III and IV). The vertical scale drawn in (I) corresponds to a length of $25 \mathrm{~mm}$.

\section{Luminous Flame Appearance in 1-g}

Observations of flame luminosity in the corresponding normal-gravity flames (burner exit conditions listed in Table 1) showed the initial transient phenomena to be eliminated well before $1 \mathrm{~s}$ after ignition. No flame flicker was observed in any of the 1-g flames examined herein, in contrast to the observations of Hegde et al. [25] who reported 1-g flicker existing even at $\operatorname{Re}<100$ for propane, propylene, or methane fuels and burner diameters of $\sim \mathrm{O}(1 \mathrm{~mm})$. To this end, the nitrogen-diluted acetylene fuel offers an advantage compared to other fuels by eliminating the unwanted influence of time variation of the 1-g flame fields due to buoyancyinduced instabilities. Figure 5 presents the luminous images of Flames I-IV, as captured from the side in 1-g at $2 \mathrm{~s}$ after ignition. The closed tips of the 1-g flames indicate their non-soot-emitting character, contrasting their soot-releasing 0-g counterparts seen in Fig. 1. In all cases, the spatial extent of the luminous zone in $1-\mathrm{g}$ is smaller compared to its 0 -g counterpart. Furthermore, the luminous zone differences between $0-\mathrm{g}$ and 1-g appear to be more pronounced for the low flow rate flame (I). Finally, fuel preheat appears to have only a slight visible effect on the structure of the soot field in 1-g; notice the gradual increase in maximum diameter of the luminous zone as shown in Figs. 5II, III, and IV. The height of the luminous flame zone appears to be unchanged $(\sim 26 \mathrm{~mm})$ under the fuel preheat levels investigated herein.

\section{1-g Soot Fields}

Radial distributions of soot volume fraction at distinct axial stations above the burner mouth of each 1-g flame were also determined. The specific heights analyzed in 1-g are $Z=5,10,15$, and $20 \mathrm{~mm}$. Figure 6 displays the radial variations of $f_{v}$ throughout the four 1-g flames (I to IV; see Table 1). Comparing the distributions of Fig. $3(0-\mathrm{g})$ and Fig. $6(1-\mathrm{g})$, it is verified that, for the same burner exit conditions, the soot field in $1 \mathrm{~g}$ is more confined compared to $0 \mathrm{~g}$. The reduced spatial extent of the soot field in 1-g is also corroborated by the luminous flame images of Figs. 1 and 5. However, the differences between $0-\mathrm{g}$ and $1-\mathrm{g}$ do not appear as large when using the luminous zone as the criterion, instead of using the soot radial distributions. This is attributed to the sensitivity of the luminous flame outline to the lens aperture used to capture an image. It is acknowledged, after all, 


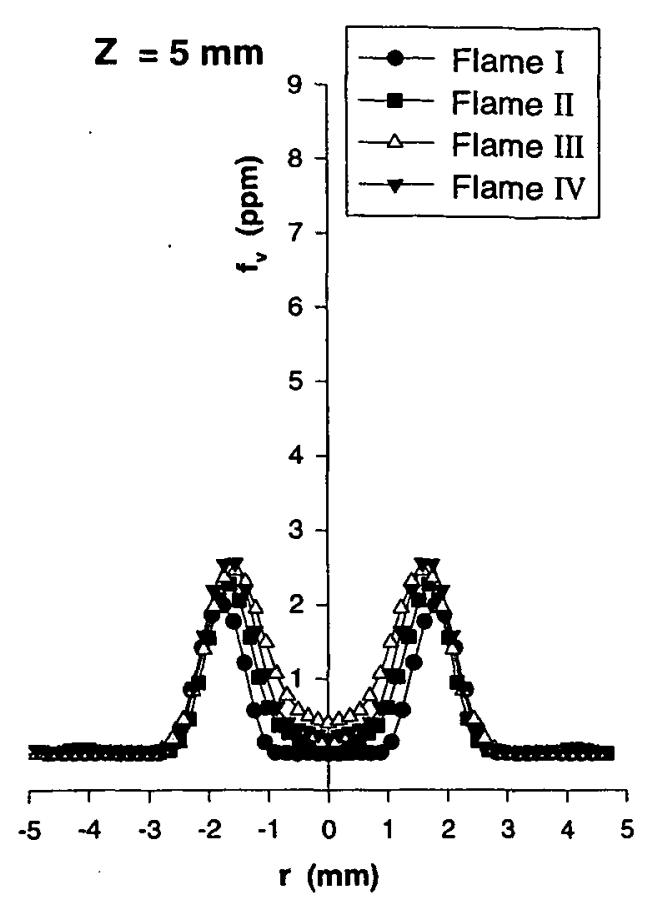

(a)

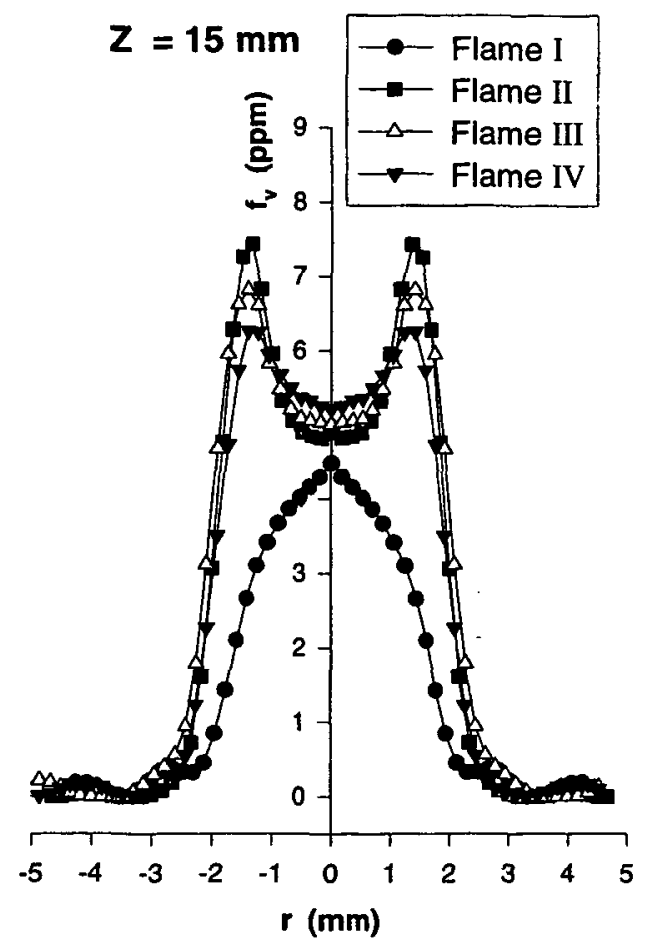

(c)

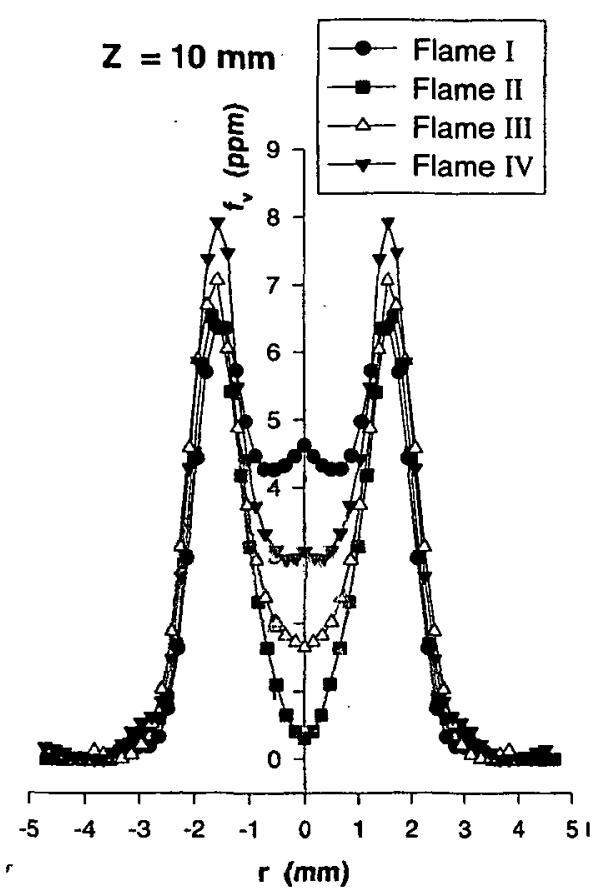

(b)

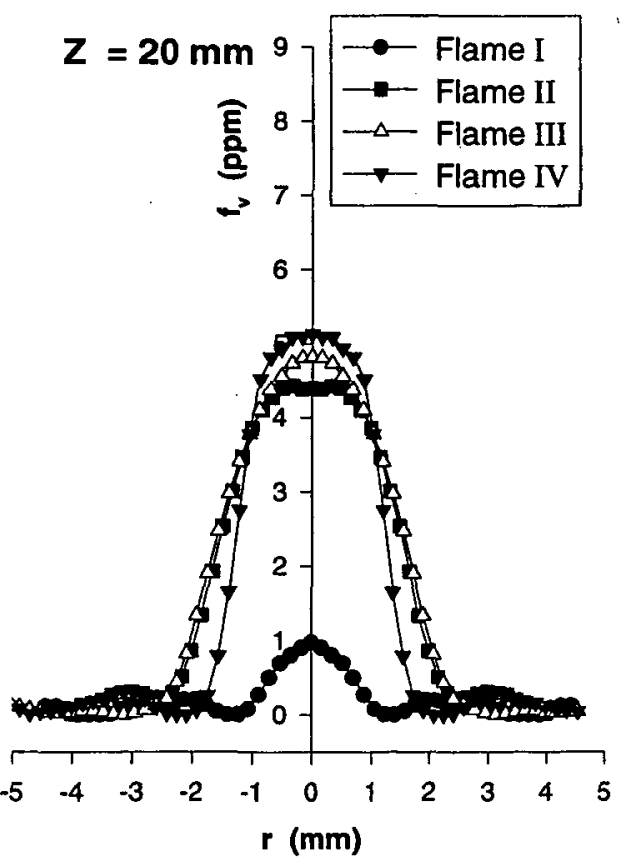

(d)

Fig. 6. Radial distributions of soot volume fraction $\left(f_{v}\right)$ at four distinct axial stations above the burner mouth of the corresponding 1-g flames (I to IV; see Table 1). Distributions at (a) $Z=5 \mathrm{~mm}$, (b) $Z=10 \mathrm{~mm}$, (c) $Z=15 \mathrm{~mm}$, and (d) $Z=20 \mathrm{~mm}$ are shown. 
that luminous zone images merely provide a qualitative measure of the spatial extent of the soot field. On the contrary, soot volume fraction distributions provide a reliable definition of the space occupied by the soot aerosol.

As expected, Fig. 6 quantifies that the streamwise extent of the soot field in Flame I (low fuel flow rate) is smaller compared to those of the other three flames. The soot volume fraction distributions displayed in this figure also reveal that most soot particles in the upper portions of the buoyant flames are convected along or near the flame centerline (see Fig. 6d), contrary to their 0 -g counterparts which are confined off the axis even past the flame tip (see Fig. 3e). The gradual buildup of soot near the flame axis in 1-g occurs despite the shorter residence times available in the presence of gravity. A comparison of the radial distributions in Fig. $6 \mathrm{c}$ and $\mathrm{d}$ supports the view that most of the soot transported along the annular region has been oxidized by $Z=20 \mathrm{~mm}$ (see absence of soot "wings" at this height). The radial distributions in Fig. 6a-c also show that for fixed mass flow rate, the burner exit velocity has no effect on the radial location of the soot annulus at a fixed axial height. However, the fuel exit velocity does have an effect on the peak value of soot volume fraction at a fixed height. The soot distributions displayed in Fig. 6d should be viewed only as indicative of the trend of the remaining unoxidized particles to concentrate near the centerline before they reach the luminous tip. The relatively narrower character of the radial distribution for Flame IV in Fig. 6d is believed to be a result of the limited spatial resolution afforded near the tip of the buoyant flames, as well as the slight lateral motion of the flame tip caused by natural convection triggered by the elevated temperature of the burner tip.

Figure 7 compares the streamwise variation of (a) maximum and (b) on-axis soot volume fraction at each height $Z$ for all 1-g flames. As the radial distributions in Fig. 6 indicate, the maximum values of $f_{v}$ at heights $Z=5,10$, and $15 \mathrm{~mm}$ correspond to the soot annulus (except for Flame I), while at $Z=20 \mathrm{~mm}$ the peak concentrations occur at the centerline. According to Fig. 7a, the overall peak values of $f_{v}$ for Flame I (low flow rate) and Flame II (unpreheated fuel) are $\sim 6.4 \mathrm{ppm}$ and $7.4 \mathrm{ppm}$, respec-

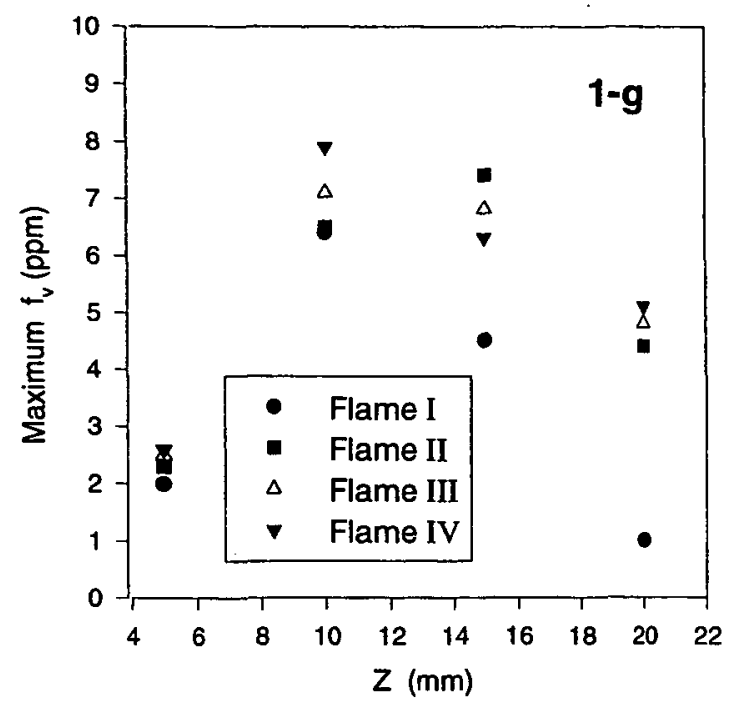

(a)

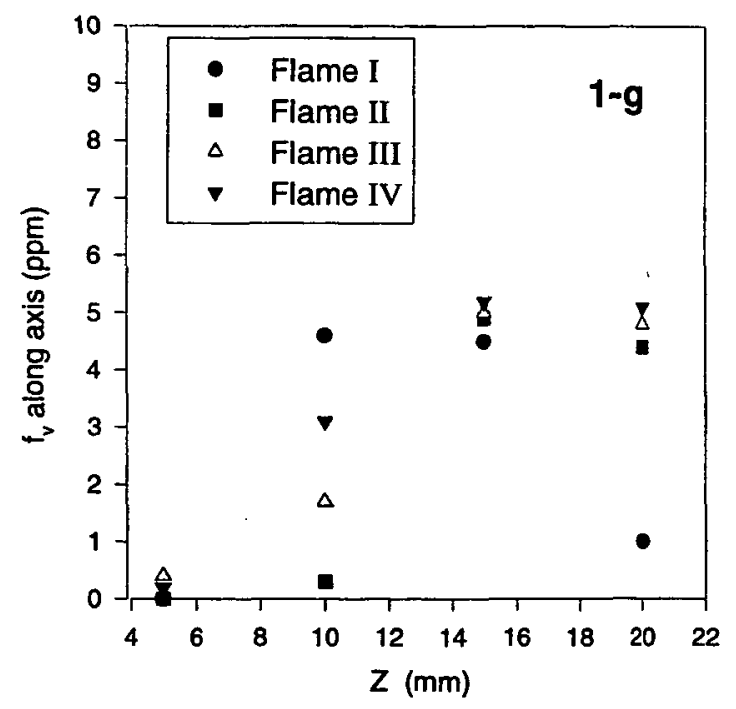

(b)

Fig. 7. Comparison of the streamwise variation of (a) maximum and (b) on-axis soot volume fraction at each height $Z$ for the $1-\mathrm{g}$ flames.

tively. These maxima are attained at or near the heights of $Z=10 \mathrm{~mm}$ (Flame $\mathrm{I}$ ) and $Z=15$ $\mathrm{mm}$ (Flame II). Comparing with the 0 -g data of Fig. $4 \mathrm{a}$, the ratio of peak values for $f_{v}$ in Flames I and II remains unaffected by the presence of gravity. Figure $7 \mathrm{a}$ also reveals that in both preheated-fuel flames the soot volume fractions 
peak at $Z=10 \mathrm{~mm}(\sim 7.1 \mathrm{ppm}$ for Flame III, $\sim 7.9 \mathrm{ppm}$ for Flame IV) and decline steadily thereafter. To this end, moderate fuel preheat in 1-g appears to shift the maximum soot volume fraction to lower heights (i.e., earlier residence times). It is emphasized that this shift, as caused by fuel preheat, has also been seen in the corresponding 0-g flames (see Fig. 4a). On the other hand, fuel preheat of $\sim 100 \mathrm{~K}$ seems to have little effect on the maximum soot loading in 1-g (contrary to what was found in 0-g; Fig. $4 a)$. Figure $7 b$, which compares the streamwise variation of $f_{\nu}$ along the centerline of the four 1-g flames, demonstrates that, for fixed mass flow rate, moderate fuel preheat enhances soot particle loading in the core of the flame, especially at intermediate heights $(Z=10 \mathrm{~mm}$, for example). While this effect was also seen in $0-\mathrm{g}$ (see Fig. 4b), it appears to be weaker in 1-g, probably due to the significantly reduced residence times under normal gravity conditions. Nevertheless, the increased soot concentrations on the centerline of preheated flames are consistent with the hypothesis that fuel preheat of $\sim 100 \mathrm{~K}$ enhances fuel pyrolysis rates, although adiabatic flame temperatures are raised by $10 \mathrm{~K}$ or less by such preheat levels.

\section{Particle Transport Considerations: Relevance to Soot Field Structure}

The soot volume fraction distributions presented in the previous sections provide static images of the spatial arrangement of the soot aerosol within the flames. Because soot growth and oxidation rates are associated with temporal changes in soot sizes, the transport of particles through the flame coordinates needs to be considered. The soot transport characteristics in a gaseous medium depend on local gas velocities and temperatures [3], temperature gradients along the cross-stream coordinate which, in turn, affect thermophoretic forces towards the cooler inner regions of the flame [21, 26], air entrainment rates, or a combination of all or some of the above. Unfortunately, neither velocity nor temperature measurements are available in the flames examined herein, thus allowing no detailed definition of the particle paths, and in turn, soot growth and oxidation rates.

The prolonged annular structure of the soot

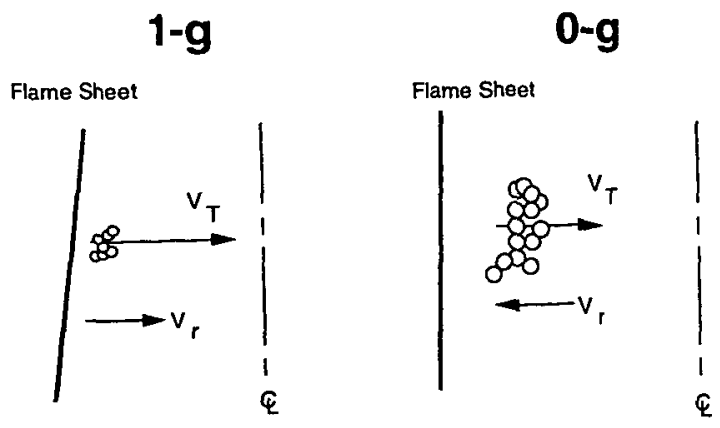

Fig. 8. Schematic illustrating the action of gas convective $\left(V_{r}\right)$ and soot thermophoretic $\left(V_{T}\right)$ radial velocities in typical $1-\mathrm{g}$ and $0-\mathrm{g}$ gas jet diffusion flames.

fields in the $0-\mathrm{g}$ flames investigated herein may be due to reduced gas temperatures in the vicinity of the flame axis which are known to inhibit the formation of carbonaceous particle precursors [3]. If the gas temperature in these regions remains low, the formation of soot is delayed, thus providing a plausible explanation for the sustained annular structure of the $0-\mathrm{g}$ soot fields. A simple estimate of the soot thermophoretic velocities is made below in order to examine the possibility of particle radial transport from the soot annular region to the flame core. The thermophoretic velocity for soot particle transport along the radial coordinate $r$ (see Fig. 8) is given by [27]

$v_{T}^{r}=-K \nu \frac{\nabla_{r} T}{T}$

where the negative sign denotes motion against the radial temperature gradient, and $\nu, T$ are, respectively, the kinematic viscosity and local temperature of the ambient gas $\left(\nu \propto T^{1.5}[28]\right)$. The coefficient $K$ depends on particle size, with values ranging from 0.3 for very large aggregates to 0.55 for small particles [29]. The measurements of Bahadori et al. [30] showed that local temperatures in $0 \mathrm{-g}$ diffusion flames are lower than in the corresponding 1-g flames. Thus, we consider local temperatures of $1600 \mathrm{~K}$ and $1200 \mathrm{~K}$ as being characteristic for the $1-\mathrm{g}$ and $0-\mathrm{g}$ flames examined herein. Typical radial temperature gradients in 1-g jet diffusion flames are of the order of $150 \mathrm{~K} / \mathrm{mm}$ (being as high as $250 \mathrm{~K} / \mathrm{mm}$ ) [26], while they are reduced in $0-\mathrm{g}$ [30]. Considering the larger aggregate size in $0-\mathrm{g}$ [31] we deduce $\left.V_{T}\right|_{1-g} /\left.V_{T}\right|_{0-g}>2$, i.e., ther- 
mophoretic velocities in 1-g are significantly stronger than those encountered in $0-\mathrm{g}$. In both cases, however, $V_{T} \sim \mathrm{O}(1 \mathrm{~cm} / \mathrm{s})$.

Figure 8 depicts schematically the relative positioning of a typical soot particle with respect to the flame sheet and the burner centerline at low heights of the $1-\mathrm{g}$ and $0-\mathrm{g}$ jet diffusion flames. In both cases, the thermophoretic velocity $V_{T}$ is exerted in the direction pointing from the high-temperature flame sheet to the symmetry axis. As seen in the preceding paragraph, thermophoretic velocities in $0-\mathrm{g}$ are weaker than those encountered in $1-\mathrm{g}$, but both are fairly weak $\sim \mathrm{O}(1 \mathrm{~cm} / \mathrm{s})$. The radial gas velocity $V_{r}$ in the vicinity of the soot particles is also drawn in Fig. 8, and shows that strong air entrainment in 1-g amplifies the effect of thermophoresis in pushing the soot inward. In 1-g it is $V_{r} \sim \mathrm{O}(10 \mathrm{~cm} / \mathrm{s})$ [26], which indicates the dominance of this mechanism in radial particle transport low in the flame. Hegde et al. [25] numerically predicted the radial distributions of axial velocity in $1-\mathrm{g}$ and $0-\mathrm{g}$ gas jet diffusion flames, and confirmed that axial velocities decrease with distance from the burner tip in $0-\mathrm{g}$. Consequently, the expanding/decelerating jet flow in 0 -g pushes the particles away from the axis, thus opposing the weaker thermophoretic force, and in turn, preventing the soot aggregates from traversing towards the flame centerline. The residence times are of the order of 100 $\mathrm{ms}$ in 1-g jet diffusion flames [26], and around $300 \mathrm{~ms}$ in their $0-\mathrm{g}$ counterparts. To this end, the prolonged residence times in 0 -g would tend to assist radial soot transport towards the core of the $0-\mathrm{g}$ flames. On the other hand, the larger radial span of the $0-\mathrm{g}$ flames inhibits soot migration from the annulus to the centerline. Even though radial transport of soot from the annulus to the vicinity of the flame axis may indeed have negligible contribution in $0-\mathrm{g}$ (as is believed to be the case in 1-g), this possibility cannot be verified at this time.

\section{CONCLUSIONS}

An experimental investigation has been presented to quantify the influence of moderate fuel preheat (temperatures up to $160^{\circ} \mathrm{C}$ ) on soot-field structure in 0-g laminar gas jet diffu- sion flames. Parallel work in 1-g was also conducted to delineate the effect of elevated fuel temperatures on soot-field structure in buoyant flames. The work was performed at the 2.2-s drop tower of the NASA Lewis Research Center. The experimental methodology implemented jet diffusion flames of nitrogen-diluted acetylene fuel burning in quiescent air at atmospheric pressure. The study utilized a full-field laser-light extinction technique capable of determining transient soot spatial distributions in laminar axisymmetric flames. The $50 \%$ (volume) $\mathrm{C}_{2} \mathrm{H}_{2} / \mathrm{N}_{2}$ fuel mixture was injected through a $1.6-\mathrm{mm}$-diameter burner with a Reynolds number $\mathrm{O}(100)$. The normal-gravity flames did not flicker and emitted no soot, while their nonbuoyant counterparts released soot from their blunt tip.

Fuel preheat of $\sim 100 \mathrm{~K}$ was found to reduce soot loadings in the annular region of the 0 -g jet diffusion flames but caused an increase in soot volume fractions on the centerline. In addition, fuel preheat reduced the spatial extent of the soot field in $0-\mathrm{g}$. In $1-\mathrm{g}$, the same fuel preheat levels had a weaker influence on soot loadings along the annular region, but were also found to enhance soot concentrations on the flame centerline. Furthermore, the spatial extent of the corresponding 1-g flames appeared to be insensitive to fuel preheat. The increased soot concentrations on the flame centerline, as caused by fuel preheat, suggest that raising the fuel temperature by $\sim 100 \mathrm{~K}$ promotes pyrolysis rates which, in turn, create more soot in this region. A common feature of both $0-\mathrm{g}$ and $1-\mathrm{g}$ flames was the shift of the peak soot volume fraction to lower heights (or likewise earlier residence times) when the fuel was preheated. This shift was insensitive to the presence of gravity for the flame conditions considered herein, and suggests that the soot growth stage is shortened both in $1-\mathrm{g}$ and $0-\mathrm{g}$ when elevated fuel temperatures are used in conjunction with a fixed fuel mass flow rate. This shift also suggests a considerable effect of burner exit conditions on soot field structure, even in the presence of strong buoyant forces which have been known to "wash out" any memory of fuel injection conditions at the burner exit. The above fuelpreheat-induced changes in the soot field in 1-g were not accompanied by any notable visible 
changes in the flame luminous height, thus suggesting that flame luminosity alone can be misleading when sooting trends are evaluated. It must be emphasized, however, that the reported results were obtained for flames burning nitrogen-diluted acetylene fuel which release soot in 0 -g but operate below their smoke point in 1-g. More studies are needed to examine if these trends are maintained over a wider range of burner exit conditions as well as other fuels.

This work has been supported by NASA under Grant No. NGT3-52300. The authors wish to thank Prof. Mun Choi and Kirk Jensen of UIC for the conveyance of the tomographic inversion programs, as well as useful discussions through the duration of the study.

\section{REFERENCES}

1. Viskanta, R., and Mengüc, M. P., Prog. Energy Combust. Sci. 13:97 (1987).

2. Hilts, P. J., New York Times, p. A1, July 19, 1993.

3. Glassman, I., Twenty-Second Symposium (Intemational) on Combustion, The Combustion Institute, Pittsburgh, 1988, p. 295.

4. Law, C. K., and Faeth, G. M., Prog. Energy Combust. Sci. 20:65 (1994).

5. Edelman, R. B., and Bahadori, M. Y., Acta Astronautica 13:681 (1986).

6. Bahadori, M. Y., Edelman, R. B., Stocker, D. P., and Olson, S. L., ALAA J. 28:236 (1990).

7: Sunderland, P. B., Mortazavi, S., Faeth, G. M., and Urban, D. L., Combust. Flame 96:97 (1994).

8. Mortazavi, S., Sunderland, P. B., Jurng, J., Köylü, Ü. O., and Faeth, G. M. (1993). AIAA Paper 93-0708.

9. Megaridis, C. M., Konsur, B., and Griffin, D. W., Twenty-Sixth Symposium (International) on Combustion, The Combustion Institute, Pittsburgh, 1996, p. 1291.

10. Greenberg, P. S., and Ku, J. C., Appl. Optics 36:5514 (1997).

11. Greenberg, P. S., and $\mathrm{Ku}, \mathrm{J}$. C., Combust. Flame 108:227 (1997).

12. Axelbaum, R. L., and Law, C. K., Twenty-Third Sym- posium (International) on Combustion, The Combustion Institute, Pittsburgh, 1990, p. 1517.

13. Gülder, Ö. L., and Snelling, D. R., Twenty-Third Symposium (International) on Combustion, The Combustion Institute, Pittsburgh, 1990, p. 1509.

14. Gülder, Ö. L., Combust. Flame 88:74 (1992).

15. Howard, J. B., and Kausch, W. J., Jr., Prog. Energy Combust. Sci. 6:263 (1980).

16. Syed, K. J., Stewart, C. D., and Moss, J. B., TwentyThird Symposium (International) on Combustion, The Combustion Institute, Pittsburgh, 1990, p. 1533.

17. Kaplan, C. R., Shaddix, C. R., and Smyth, K. C., Combust. Flame 106:392 (1996).

18. Lekan, J., Gotti, D. J., Jenkins, A. J., Owens, J. C., and Johnston, M. R. (1996). Users Guide for the 2.2 Second Drop Tower of the NASA Lewis Research Center, NASA TM-107090.

19. Dobbins, R. A., and Megaridis, C. M., Appl. Optics 30:4747 (1991).

20. Dasch, C. J., Appl. Optics 31:1146 (1992).

21. Santoro, R. J., Semerjian, H. G., and Dobbins, R. A., Combust. Flame 51:203 (1983).

22. Köylü, Ü. Ö., and Faeth, G. M., J. Heat Transfer 116:152 (1994).

23. Julien, R., and Botet, R., Aggregation and Fractal Aggregates. World Scientific, Singapore, 1987.

24. Honnery, D. R., and Kent, J. H., Combust. Flame 82:426 (1990).

25. Hegde, U., Zhou, L., and Bahadori, M. Y., Combust. Sci. Technol. 102:95 (1994).

26. Santoro, R. J., Yeh, T. T., Horvath, J. J., and Semerjian, H. G., Combust. Sci. Technol. 53:89 (1987).

27. Friedlander, S. K., Smoke, Dust and Haze. John Wiley, New York, 1977, p. 43.

28. Svehla, R. A. (1962). Estimated Viscosities and Thermal Conductivities of Gases at High Temperatures, NASA TR R-132.

29. Talbot, L., Cheng, R. K., Schefer, R. W., and Willis, D. R., J. Fluid Mechanics 101:737 (1980).

30. Bahadori, M. Y., Stocker, D. P., Vaughan, D. F., Zhou, L., and Edelman, R. B., in Modern Developments in Energy, Combustion and Spectroscopy (F. A. Williams, A. K. Oppenheim, D. B. Olfe, and M. Lapp, Eds.), Pergamon Press, Oxford, 1993, p. 49.

31. Ku, J. C., Griffin, D. W., Greenberg, P. S., and Roma, J., Combust. Flame 102:216 (1995).

Received 26 March 1997; accepted 24 September 1997

This report is a preprint of an article submitted to a journal for publication. Because of changes that may be made before formal publication, this preprint is made available with the understanding that it will not be cited or reproduced without the permission of the author. 